\title{
Anemia among HIV Infected Individuals Taking ART with and without Zidovudine at Addis Ababa, Ethiopia
}

\author{
Zemenu Tamir ${ }^{*}$, Jemal Alemu ${ }^{1}$, Aster Tsegaye ${ }^{1}$
}

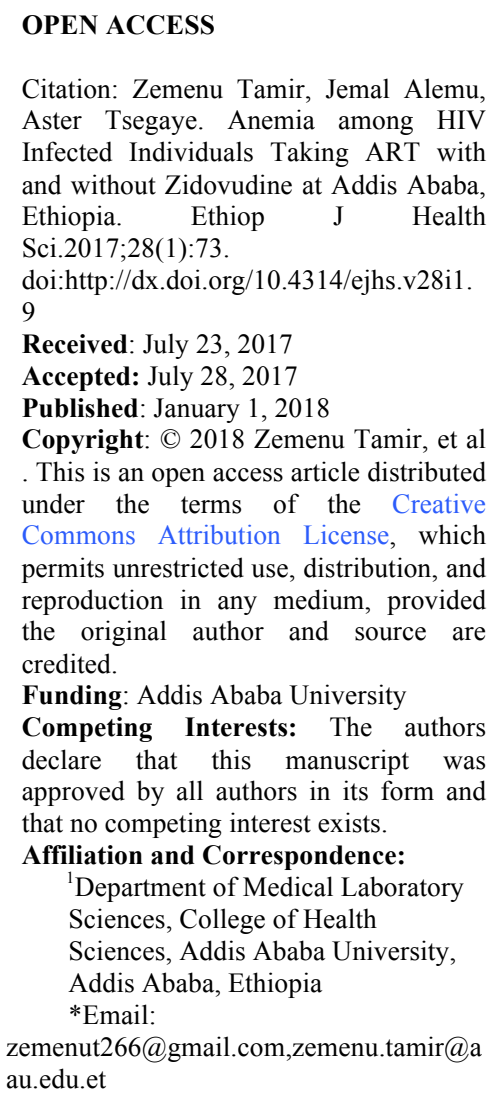

\section{ABSTRACT}

BACKGROUND: Hematological complications such as Zidovudine(ZDV) associated anemia are among the commonly reported adverse drug reactions of Antiretroviral Therapy(ART). Little is known about ZDV associated anemia in developing countries like Ethiopia.

METHODS: Comparative retrospective cohort study was conducted at the ART Clinic of St. Paul Hospital Millennium Medical College from February 2011 to December 2012 to characterize anemia among HIV/AIDS patients initiated with ZDV and non-ZDV containing ART regimens. In each group, $197 \mathrm{HIV}$ infected adults who had complete medical records were included. Medical records of participants were reviewed using pre-tested data collection format. Data were analyzed using SPSS version 19 for windows. For all statistical significance tests, the cut-off value was $P<0.05$. RESULTS: Among ZDV group, anemia prevalence was $20.8 \%$ (41/197), 33.5\%(66 /197) and 13\%(19/146) at baseline, six and twelve months of ART follow-up, respectively. On the other hand in non-ZDV group, anemia was present among 44.2\% (87/197), $18.3 \%$ (36/197) and 12.4\% (25/202) of participants at baseline, six and twelve months of ART follow-up, respectively. After six months of follow-up, ZDV associated anemia was present among $32.7 \%$ (51/156) of the participants, and $43.1 \%$ of them were severe while about $45.2 \%$ were macrocytic type. Zidovudine group participants were 3.34 times more likely to develop severe anemia than non$Z D V$ group, $P<0.001$.

CONCLUSION: The prevalence, severity and characteristics of anemia were different between $Z D V$ and non-ZDV group participants at different follow-up periods of ART. Zidovudine had significant contribution to severe anemia incidence after six months of ART; thus, hemoglobin level monitoring with red cell indices is suggested for improved detection of zidovudine associated anemia. KEYWORDS: Anemia, Zidovudine, HIV/AIDS, ART, Ethiopia 


\section{INTRODUCTION}

Anemia is the most common and serious hematological complication of both Human Immunodeficiency Virus (HIV) infection and its treatment $(1,2)$. Depending on the study setting, the prevalence of anemia in HIV patients varies considerably. Close to $95 \%$ of HIV infected patients before the initiation of Antiretroviral Therapy (ART) and up to $46 \%$ of patients taking ART develop anemia at some point during the course of their disease $(3,4)$. Anemia in these patients might be caused by a wide range of etiologic factors leading to decreased red blood cell (RBC) production, increased RBC destruction, or ineffective $\mathrm{RBC}$ production $(5,6)$. Studies indicated that anemia among ART naïve HIV/AIDS patients was associated with much faster rate of disease progression and decreased quality of life, and was a strong prognostic marker for death (7-9).

Antiretroviral Therapy was generally taken as an effective treatment for reduction of anemia in HIV infection by inhibiting the progress of the disease (10). However, Zidovudine (ZDV), an element of some ART regimens and one of the first-line antiretroviral drugs for treating HIV infected adults in low resource countries (11), is identified as the commonest cause of drug associated anemia $(12,13)$. The proposed mechanism of anemia causation during ZDV therapy is inhibition of hemoglobin synthesis, globin gene transcription and proliferation of blood cell progenitor in a time and dose dependent fashion (12-14). A study conducted in the United States of America to compare the incidence of anemia in patients treated with ZDV containing and non-ZDV containing ART revealed that patients initiated with ZDV containing ART were at greater risk of developing new anemia or worsening anemia than patients initiated with nonZDV containing ART drug regimens (15).

Although the current World Health Organization (WHO) ART guideline did not recommend $\mathrm{ZDV}$ containing regimens as a preferred regimen (16), some resource constrained countries like Ethiopia continue to use ZDV-based regimens as an alternative first line drug regimen (17). Studies indicated that side effects of ART drugs studied in western (developed) nations may not be representative of developing countries such as Ethiopia since socio-economic constraints, host genetics, co-morbid conditions and nutritional intake are the risk factors for adverse drug reactions (18).

The magnitude and characteristics of ZDV associated anemia among Ethiopian patients has not been well documented. Thus, the aim of this study was to provide a comparative information about the magnitude, severity and characteristics of anemia among HIV/AIDS patients initiated with ZDV and non-ZDV containing ART regimens at baseline, after six and twelve months of ART follow-up.

\section{METHODS}

Study Setting and Population: A comparative retrospective study was conducted by reviewing hospital data of patients who were receiving ART at the ART Clinic of St. Paul Hospital Millennium Medical College(SPHMMC), Addis Ababa Ethiopia. The ART Clinic of the hospital started provision of ART service in 2003. A well recorded HIV/AIDS data were available at the hospital, and data from February 2011 to December 2012 were used for this study.

All eligible HIV/AIDS patients who initiated ART between February 2011 and December 2012; had complete demographic, laboratory and clinical records; and had at least six months of ART follow-up at the ART Clinic of SPHMMC were included. Study participants were assigned into two groups based on presence or absence of ZDV in the starting ART regimen; ZDV containing ART initiated group (ZDV group) and non-ZDV containing ART initiated group (non-ZDV group). Hence, a total of 394 HIV infected individuals' data, 197 in each group, were assessed. Data of pregnant HIV/AIDS patients and that of those who had identified opportunistic infections were excluded from the study since both could lead to anemia themselves.

DOI: http://dx.doi.org/10.4314/ejhs.v28i1.9 
Before collection of the data, a data extraction tool was prepared and pre-tested. Two ART trained nurses and one laboratory technologist were selected and given a one day training on the data extraction tool and how to collect data from registers to ensure no selection or information bias would be introduced at the time of data collection. The principal investigator supervised the data collectors and examined the tools for accuracy and completeness.

The data collection tool contains the participants' demographic variables, ART outcome, WHO clinical stage, type of ART regimen and immune-hematological parameters. Each variable was carefully extracted from ART log book, patient follow-up cards and laboratory information system computer records at baseline (before ART initiation), after six months and 12 months of ART follow-up. In the absence of same day data, the data which was collected in the closest day before the date of ART initiation (up to one week before date of ART initiation) was considered as the baseline data.

\section{RESULTS}

Demographic and Clinical Characteristics of the Study Participants: In this study, a total data of 394 HIV infected individuals (197 in ZDV and 197 in non-ZDV group) were included. The majority of the study participants were females (60.4\% vs. $67.5 \%$ in ZDV and non-ZDV group, respectively). At baseline, ZDV group participants were relatively younger with median (interquartile range) (IQR) age of 34.0[28-40] vs. 35.0[29-42] years, were at advanced WHO clinical stage (stage III or IV) $(54.3 \%$ vs. $63.4 \%)$ and had significantly higher proportion of working patients $(90.4 \%$ vs. $78.7 \%) \quad(\mathrm{P}=0.002)$ than non-ZDV group participants, respectively (Table 1 ).

At treatment initiation, ZDV group participants had significantly higher median weight with median [IQR] of 55[49.5-62.0] vs. 52 [46-60.5] $\mathrm{kg}(\mathrm{P}=0.002)$ than non-ZDV group participants. Similarly, they had also higher median hemoglobin concentration with median [IQR] of 13.7 [12.4-14.7] g/dl vs. 12.5[10.8-13.9] $\mathrm{g} / \mathrm{dl})(\mathrm{P}=0.001)$ and higher median MCHC with median [IQR] of 33.25[32.1-34.32] vs. 32.4[31.533.72] $\mathrm{g} / \mathrm{dl} \quad(\mathrm{P}=0.01)$ than non-ZDV graoup participants (Table 1).

After six months of follow-up, a total of 46 individuals were lost from follow-up (dropouts); majority of them $(25 / 46)$ were from non-ZDV group. Among the dropouts, 21.7\% (10/46) were anemic either at baseline or at six months of followup. There was also switching from ZDV group to non-ZDV group and vice versa, thirty one and one participant, respectively.

Magnitude, Severity and Characteristics of Anemia: Anemia was present among $20.8 \%$ (41/197) and 33.5\% (66/197) of ZDV group participants at baseline and six months of ART follow-up, respectively, which showed a statistically significant increment of anemia prevalence, $\mathrm{P}=0.006$. On the other hand, in the non-ZDV group, anemia was present among $44.2 \%(87 / 197)$ and $18.3 \%(36 / 197)$ of patients at baseline and six months of follow up respectively, with statistically significant decrease of anemia prevalence, $\mathrm{P}<0.001$ (Table 2).

Due to loss to follow-up and switching after six months of treatment, number of participants at twelve months of follow-up in the ZDV and nonZDV groups were 146 and 202, respectively. Of these participants, anemia was present among $19(13 \%)$ and $25(12.4 \%)$ participants in ZDV and non-ZDV group, respectively (Table 2).

In the ZDV group, anemia was predominantly mild at baseline $(65.9 \%)$ and after twelve months (73.7\%) of ART but severe (42.4\%) after six months of ART. The majority of the anemia at baseline and after six months of followup were of normocytic type $(63.4 \%$ and $53.1 \%$, respectively) while macrocytic anemia (68.4\%) was the dominant finding after twelve months of followup (Table 2).

In the non-ZDV group, anemia was of moderate type at baseline in the majority of them $(55.2 \%)$, but mild anemia was dominant after six months (58.3\%) and twelve months (56\%) of follow-up. In this group, normocytic anemia was the dominant finding at baseline $(75.8 \%)$, after six months $(75.0 \%)$ and twelve months $(64 \%)$ of ART follow-up (Table 2).

DOI: http://dx.doi.org/10.4314/ejhs.v28i1.9 
Ethiop J Health Sci.

Vol. 28, No. 1

January 2018

Table 1: Comparison of demographic and immune-hematological characteristics of ZDV group and nonZDV group participants at baseline $\left(\mathrm{n}_{1}=\mathrm{n}_{2}=197\right)$ at ART clinic of SPHMMC, from February 2011 to December 2012.

\begin{tabular}{|c|c|c|c|}
\hline Characteristics & ZDV group & Non-ZDV group & P-value \\
\hline \multicolumn{4}{|l|}{ Gender, n (\%) } \\
\hline Male & $78(39.6)$ & $64(32.5)$ & \multirow[t]{2}{*}{0.86} \\
\hline Female & $119(60.4)$ & $133(67.5)$ & \\
\hline Age (years), median(IQR) & $34.0(28-40)$ & $35.0(29-42)$ & 0.48 \\
\hline \multicolumn{4}{|l|}{ Age group (years), n(\%) } \\
\hline $18-24$ & $13(6.6)$ & $12(6.1)$ & \multirow{4}{*}{0.485} \\
\hline $25-34$ & $93(47.2)$ & $86(43.7)$ & \\
\hline $35-44$ & $61(31.0)$ & $57(28.9)$ & \\
\hline$\geq 45$ & $30(15.2)$ & $42(21.3)$ & \\
\hline \multicolumn{4}{|l|}{ WHO Stage, n (\%) } \\
\hline Less advanced (Sage I or II) & $90(45.7)$ & $74(37.6)$ & \multirow[t]{2}{*}{0.125} \\
\hline Advanced (Stage III or IV) & $107(54.3)$ & $123(63.4)$ & \\
\hline Weight (in Kg), median(IQR) & $55(49.5-62.0)$ & $52(46-60.5)$ & 0.002 \\
\hline \multicolumn{4}{|l|}{ Weight group, n(\%) } \\
\hline$\geq 50 \mathrm{~kg}$ & $148(75.1)$ & $124(62.9)$ & \multirow[t]{2}{*}{0.012} \\
\hline$<50 \mathrm{~kg}$ & $49(24.9)$ & $73(37.1)$ & \\
\hline \multicolumn{4}{|l|}{ Functional status,n(\%) } \\
\hline Working & $178(90.4)$ & $155(78.7)$ & \multirow[t]{2}{*}{0.002} \\
\hline Not-working & $19(19.6)$ & $42(21.3)$ & \\
\hline $\mathrm{CD4}^{+} \mathrm{T}$-cell$\left(\right.$ cells $\left./ \mathrm{mm}^{3}\right)$, median $(\mathrm{IQR})$ & $149(82-199)$ & $155(88-201)$ & 0.762 \\
\hline \multicolumn{4}{|l|}{$\mathrm{CD4}^{+}$T-cell $\left(\right.$cells $\left./ \mathrm{mm}^{3}\right), \mathrm{n}(\%)$} \\
\hline$<50$ & $18(9.1)$ & $27(13.7)$ & \multirow[t]{4}{*}{0.382} \\
\hline $50-199$ & $134(68)$ & $119(60.4)$ & \\
\hline $200-349$ & $38(19.3)$ & $43(21.8)$ & \\
\hline$\geq 350$ & $7(3.6)$ & $8(4.1)$ & \\
\hline Hemoglobin conc.(g/dl), median(IQR) & $13.7(12.4-14.7)$ & $12.5(10.8-13.9)$ & 0.001 \\
\hline $\operatorname{MCV}(f l)$, median(IQR) & $88(83.3-92.7)$ & $87.9(82.8-92.15)$ & 0.9999 \\
\hline $\operatorname{MCHC}(\mathrm{g} / \mathrm{dl})$, median(IQR) & $33.25(32.1-34.37)$ & $32.4(31.5-33.77)$ & $\mathbf{0 . 0 1}$ \\
\hline
\end{tabular}

Incident Anemia: Incident anemia after treatment initiation was assessed by restricting the analysis on data of participants who were non-anemic at baseline. Accordingly, a total of 266 participants, 156 in ZDV group and 110 in non-ZDV group, were free from anemia at baseline. Similarly, 174 participants, 89 among the ZDV group and 85 among non-ZDV group, were free from anemia both at baseline and six months of follow-up. Incident anemia at six months of follow-up was recorded in $32.7 \%(51 / 156)$ and $8.2 \%(9 / 110)$ of participants among the ZDV group and the nonZDV group described as ZDV associated and non-ZDV associated anemia, respectively. After twelve months of follow-up, the prevalence of ZDV associated and non-ZDV associated incident anemia was $12.4 \%(11 / 89)$ and $7.1 \%(6 / 85)$, respectively (Table 3 ). 
Table 2: Prevalence, severity and type of anemia among ZDV and Non-ZDV group participants at baseline, six and twelve months of ART follow up at ART clinic of SPHMMC, from February 2011December 2012.

\begin{tabular}{|c|c|c|c|c|c|c|}
\hline \multirow[t]{3}{*}{ Characteristics } & \multicolumn{6}{|c|}{ Study participants } \\
\hline & \multicolumn{3}{|c|}{ ZDV group } & \multicolumn{3}{|c|}{ Non-ZDV group } \\
\hline & $\begin{array}{c}\text { Baseline } \\
(\mathrm{n}=197)\end{array}$ & $\begin{array}{r}6 \text { month } \\
(\mathrm{n}=197)\end{array}$ & $\begin{array}{l}12 \text { month } \\
(\mathrm{n}=146)^{* *}\end{array}$ & $\begin{array}{c}\text { Baseline } \\
(\mathrm{n}=197)\end{array}$ & $\begin{array}{l}6 \text { month } \\
(\mathrm{n}=197)\end{array}$ & $\begin{array}{l}12 \text { month } \\
(\mathrm{n}=\mathbf{2 0 2}) \dagger\end{array}$ \\
\hline \multicolumn{6}{|l|}{ Anemia severity, n (\%) } & $25(12.4)$ \\
\hline Mild & 9) & ) & $14(73.7)$ & $35(40.2)$ & $21(58.3)$ & $14(56)$ \\
\hline Mode & & & $-\sigma^{\prime}$ & & & \\
\hline Severe & & & - & $4(4.6)$ & & \\
\hline \multicolumn{7}{|l|}{ Anemia type ,\% } \\
\hline Microcytic-hypochro & 7 & 3 & - & $6.9 \%$ & $2.8 \%$ & $8 \%$ \\
\hline Mic & & 3 & - & $\%$ & $2.8 \%$ & $4 \%$ \\
\hline ic & $31.7 \%$ & 18. & $21.1 \%$ & $37.9 \%$ & $38.9 \%$ & $16 \%$ \\
\hline No & & & & $37.9 \%$ & & \\
\hline $\mathrm{Mac}$ & - & 4.5 & 15. & - & 5.5 & $12 \%$ \\
\hline Macr & $7.3 \%$ & $36.4 \%$ & $52.6 \%$ & $3.5 \%$ & $13.9 \%$ & $12 \%$ \\
\hline \multicolumn{7}{|c|}{$\begin{array}{l}\text { The number increased due to drug regimen shift from ZDV group to non-ZDV group } \\
{ }^{* *} \text { The number of participants decreased due to regimen shift from ZDV group to non-ZDV group and lost to follow-up }\end{array}$} \\
\hline \multicolumn{3}{|c|}{$\begin{array}{l}\text { Incident anemia at six months of ART follow-up } \\
\text { had a significant association with } \mathrm{ZDV} \text { containing } \\
\mathrm{ART}, \mathrm{P}<0.001 \text {; baseline body weight, } \mathrm{P}=0.047 \text { and } \\
\text { age of participants, } \mathrm{P}=0.017 \text {. However, it did not } \\
\text { show significant association with sex, } \mathrm{P}=0.854 \text {; } \\
\text { WHO clinical stage, } \mathrm{P}=0.426 \text {; functional status, } \\
\mathrm{P}=0.93 \text {; and baseline CD } 4 \text {-cell count, } \mathrm{P}=0.182 \\
\text { [Table 4]. } \\
\text { The majority of the incident anemia cases } \\
\text { among the ZDV group were severe }(43.1 \%) \text { after } \\
\text { six months and mild ( } 63.6 \%) \text { after twelve months of } \\
\text { follow-up. In the non-ZDV group, } 88.9 \% \text { and } \\
83.3 \% \text { of incident anemia cases were mild at six and } \\
\text { twelve months of follow-up, respectively (Table } 3 \text { ). } \\
\text { Zidovudine group participants were } 3.34 \text { times more } \\
\text { likely to develop severe anemia than non-ZDV }\end{array}$} & \multicolumn{4}{|c|}{$\begin{array}{l}\text { group participants, } \mathrm{RR}=3.34,95 \% \text { CI of }[1.95 \text {, } \\
5.52], \mathrm{P}<0.001 \text {. } \\
\text { The majority of incident anemia cases were } \\
\text { normocytic type }(58.3 \%) \text { after six months and } \\
\text { macrocytic }(53 \%) \text { after twelve months of ART } \\
\text { follow-up. There was a remarkably higher } \\
\text { proportion of macrocytic anemia cases among the } \\
\text { ZDV group }(45.2 \% \text { and } 72.7 \%) \text { than the non- } \\
\text { ZDV group }(11.1 \% \text { and } 16.7 \%) \text { after six and } \\
\text { twelve months of follow-up, respectively (Table } \\
\text { 3). Macrocytic anemia development after six } \\
\text { months of follow-up had a significant association } \\
\text { with ZDV containing ART, and the risk of } \\
\text { macrocytosis in ZDV group participants was } 2.1 \\
\text { times than that of their non-ZDV counterparts, } \\
\text { RR = } 2.1 \text {, 95\% CI [1.019, 4.346], P=0.024. }\end{array}$} \\
\hline
\end{tabular}

DOI: http://dx.doi.org/10.4314/ejhs.v28i1.9 
Table 3: Comparative prevalence, severity and characteristics of incident anemia among ZDV group and Non-ZDV group participants after six and twelve months of ART follow up at ART clinic of SPHMMC from February 2011 to December 2012.

\begin{tabular}{lcccccc}
\hline \multirow{2}{*}{ Characteristics } & \multicolumn{2}{c}{ Total } & \multicolumn{2}{c}{ ZDV group } & \multicolumn{2}{c}{ Non-ZDV group } \\
\cline { 2 - 7 } & After 6 & After 12 & After 6 & After 12 & After 6 & After 12 \\
\cline { 2 - 7 } & Month & months & months & months & month & months \\
\hline Number of participants & 266 & 174 & 156 & 89 & 110 & 85 \\
Incident anemia (n (\%)) & $60(25.6)$ & $17(9.8)$ & $51(32.7)$ & $11(12.4)$ & $9(8.2)$ & $6(7.1)$ \\
Anemia Severity (n (\%)) & & & & & & \\
Severe & $22(36.7)$ & - & $22(43.1)$ & - & - & - \\
Moderate & $9(15)$ & $4(23.5)$ & $8(15.7)$ & $4(36.4)$ & $1(11.1)$ & $1(16.7)$ \\
Mild & $29(48.3)$ & $13(76.5)$ & $21(41.2)$ & $7(63.6)$ & $8(88.9)$ & $5(83.3)$ \\
Anemia Type, n (\%) & & & & & & \\
Microcytic-Hypochromic & - & $4(23.5)$ & - & $2(18.2)$ & - & $2(33.3)$ \\
Microcytic-Normochromic & $1(1.7)$ & $4(23.5)$ & $1(1.9)$ & $1(9.1)$ & - & $3(50.0)$ \\
Normocytic -Hypochromic & $14(23.3)$ & - & $8(15.7)$ & - & $6(66.7)$ & - \\
Normocytic -Normochromic & $21(35)$ & - & $19(37.2)$ & - & $2(22.2)$ & - \\
Macrocytic-Hypochromic & $3(5)$ & $4(23.5)$ & $3(6)$ & $3(27.3)$ & - & $1(16.7)$ \\
Macrocytic-Normochromic & $21(35)$ & $5(29.5)$ & $20(39.2)$ & $5(45.4)$ & $1(11.1)$ & - \\
& & & & & & \\
\hline
\end{tabular}

\section{DISCUSSION}

The aim of this study was to provide comparative information about the magnitude and characteristics of anemia among HIV/AIDS patients initiated with ZDV and non-ZDV containing ART drug regimens. Our study showed that at treatment initiation anemia was present among $20.8 \%$ and $44.2 \%$ of $\mathrm{ZDV}$ containing and non-ZDV containing ART drug regimens initiated participants, respectively. The higher prevalence of anemia among the non-ZDV group was a reflection of the recommendation of the national HIV/AIDS treatment guideline of Ethiopia which indicates initiation of patients with lower hemoglobin concentration on nonZDV containing ART drug regimens (21). This study revealed that in the majority of the cases, anemia was mild among the ZDV group (65.9\%) and moderate $(55.2 \%)$ among the non-ZDV group. In addition, in $92 \%$ of the cases of anemia were characterized by normocytic or microcytic RBC morphology. This was in agreement with other studies which reported that anemia among ART naïve HIV/AIDS patients was mostly mild and had microcytic or normocytic blood picture which is the feature of anemia of chronic diseases (22-24).

Different studies report controversial results on the status of anemia during ART follow-up. Some studies claim that treating HIV infection with antiretroviral drugs generally improves anemia, even when specific treatment for anemia is not provided $(10,25-27)$. In support of this, a study conducted in South Africa revealed improvement of hemoglobin levels regardless of magnitude of immunosuppression and ART initiating regimens (28). On the other hand, several studies found that ART regimens containing ZDV cause anemia due to the heamatotoxic effect of ZDV which is observed in most of the patients within 3-6 months and is reversible $(15,18,29,30)$. This study showed that among the non-ZDV group, anemia improved from prevalence of $44.2 \%$ at baseline to $18.3 \%$ after six months and to $12.4 \%$ after twelve

DOI: http://dx.doi.org/10.4314/ejhs.v28i1.9 
months of ART follow-up. However, among ZDV group participants, despite having higher median hemoglobin concentration than non-ZDV group counterparts at baseline, there was increment of anemia prevalence from $20.8 \%$ at baseline to $33.5 \%$ after six months of ART follow-up. This finding was supported by the finding of Zhou et al which indicated that patients initiated with ZDVcontaining ART had an increased risk of developing anemia when compared with those initiating non-ZDV containing ART regimens (31).

Table 4: Association of baseline characteristics with incident anemia after six months of ART follow up $(\mathrm{n}=256)$ at ART clinic of SPHMMC from February 2011 to December 2012.

\begin{tabular}{|c|c|c|c|}
\hline \multirow[t]{2}{*}{ Variable } & \multicolumn{2}{|c|}{ Incident Anemia } & \multirow[t]{2}{*}{ p-value } \\
\hline & Yes, $n(\%)$ & No, n $(\%)$ & \\
\hline \multicolumn{4}{|l|}{ ART regimen } \\
\hline ZDV group & $51(32.7)$ & $105(67.3)$ & \multirow[t]{2}{*}{$<0.001$} \\
\hline Non-ZDV group & $9(8.2)$ & $101(91.8)$ & \\
\hline \multicolumn{4}{|l|}{ Sex } \\
\hline Male & $21(21.4)$ & $77(78.6)$ & \multirow[t]{2}{*}{0.854} \\
\hline Female & $39(23.2)$ & $129(76.8)$ & \\
\hline \multicolumn{4}{|l|}{ Age in years } \\
\hline $18-24$ & $6(31.6)$ & $13(68.4)$ & \multirow[t]{4}{*}{0.017} \\
\hline $25-34$ & $33(29.2)$ & $80(70.8)$ & \\
\hline $35-44$ & $13(15.5)$ & $71(84.5)$ & \\
\hline$\geq 45$ & $8(16)$ & $42(84)$ & \\
\hline \multicolumn{4}{|c|}{ WHO Clinical Stage } \\
\hline Stage I & $15(23.8)$ & $48(76.2)$ & \multirow[t]{4}{*}{0.426} \\
\hline Stage II & $27(29.8)$ & $40(70.2)$ & \\
\hline Stage III & $21(18.8)$ & $91(81.2)$ & \\
\hline Stage IV & $7(20.6)$ & $27(79.4)$ & \\
\hline \multicolumn{4}{|c|}{ CD4+ T-Cell Count (cells/ $\mu \mathrm{l})$} \\
\hline$<50$ & $5(27.8)$ & $13(72.2)$ & \multirow[t]{3}{*}{0.182} \\
\hline 50-199 & $43(24.3)$ & $134(75.7)$ & \\
\hline$\geq 200$ & $12(16.9)$ & $59(83.1)$ & \\
\hline \multicolumn{4}{|c|}{ Weight of Participants (kg) } \\
\hline$<50$ & $23(31.5)$ & $50(68.5)$ & \multirow[t]{2}{*}{0.047} \\
\hline$\geq 50$ & $37(19.2)$ & $156(80.8)$ & \\
\hline \multicolumn{4}{|l|}{ Functionality } \\
\hline Working & $53(22.3)$ & $185(77.7)$ & \multirow[t]{2}{*}{0.93} \\
\hline Not-working & $7(25))$ & $21(75)$ & \\
\hline
\end{tabular}

Similarly, in this study, incident anemia was present among $32.7 \%$ and $12.4 \%$ of the ZDV group participants and $8.2 \%$ and $7.1 \%$ of the nonZDV group participants after six and twelve months of ART follow-up, respectively. A study conducted in the US reported that the incidence of anemia was 24.6 and 8.1 per 100 person years in ZDV and non ZDV cohorts after six months of follow-up. They also proved that the incidence was higher in ZDV cohorts than non-ZDV cohorts, and had highest incidence within six months of follow-up (15). A study conducted at

DOI: http://dx.doi.org/10.4314/ejhs.v28i1.9 
St. Paul and ALERT hospitals in Addis Ababa, Ethiopia, also revealed 40.6 and 22.8 per 100 person years incidence of anemia after six months of follow-up of ZDV and non-ZDV containing ART regimens, respectively(32). The observed difference may be due to the difference in the definition of anemia, methodology of the research (for example, the US study included ART experienced patients while the Ethiopian study included patients with opportunistic infections which could induce or exacerbate anemia themselves), as well as differences in population characteristics between Americans and Ethiopians.

Zidovudine may also lead to macrocytosis of RBCs through its assumed mechanism of impairing the nuclear clock responsible for cell division thus causing enlarged cells to be produced (33). In this study, there was a remarkable proportion of macrocytic anemia development among the ZDV group (45.2\% and $72.7 \%$ ) when compared to non-the ZDV group $(11.1 \%$ and $16.7 \%)$ after six and twelve months of ART follow-up, respectively. Accordingly, ZDV group participants had a double risk of macrocytosis than their non-ZDV group counterparts after six months of ART follow-up. This was supported by other studies which revealed a higher incidence of macrocytosis among ZDV containing ART treated individuals than controls (33) and higher peripheral smear macrocytic changes after taking ZDV containing ART (30).

The incidence of severe anemia in the ZDV group patients, $14.1 \%$, was higher than reports from Uganda and Zimbabwe (6.6\%) (4) and India (9.4\%) (34). The observed difference may be due to variations in the definition of severe anemia $(\mathrm{Hb} \leq 6.5 \mathrm{~g} / \mathrm{dl}$ in the other studies and $\mathrm{Hb}<8 \mathrm{~g} / \mathrm{dl}$ in our study) and population heterogeneity.

The strength of our study was the use of routine clinical data collected from a real life clinical setting to describe anemia comparatively among HIV/AIDS patients on ZDVand non-ZDV containing ART, on which information was limited among Ethiopian participants. However, the findings of this study should be considered alongside its limitations. Since the data was collected from a routine ART service and the criteria of putting patients on the ZDV group or the non-ZDV group was merely based on the starting ART regimen, the study was not a strictly matched comparative study. In addition, we did not collected information on other clinical conditions that may be possible underlining causes of anemia at baseline. Rather, we excluded those with identified opportunistic infections that could induce anemia themselves and pregnant women, since our main objective was to describe ZDV associated anemia.

Generally, this study showed that there was a difference in anemia prevalence, severity and characteristics at initiation, after six months and twelve months of ART follow-up among ZDV containing and non-ZDV containing ART drug regimen initiated participants. It revealed that ZDV had a significant contribution to severe anemia incidence within six months of ART follow-up, the majority of which were described as macrocytic anemia type. Thus, monitoring hemoglobin levels using simple and inexpensive hemoglobin measurement methods along with measurement of red cell indices over the first six months on ART is suggested for improved detection of ZDV associated anemia.

\section{REFERENCES}

1. Sloand E. Hematologic complications of HIV infection. AIDS Rev. 2005;7(4):187-96.

2. Dikshit B, Wanchu A, Sachdeva K, Sharma A, Das R. Profile of hematological abnormalities of Indian HIV infected individuals. BMC Blood Disorders 2009, 9(5). doi: 10.1186/1471-2326-9-5.

3. Belperio PS, Rhew DC. Prevalence and outcomes of anemia in individuals with human immunodeficiency virus: a systematic review of the literature. Am J Med 2004, 116: 7. $27 \mathrm{~S}-43 \mathrm{~S}$.

4. Ssali F, Stöhr W, Munderi P, Reid A, Walker $\mathrm{S}$, Gibb D, et al. Prevalence, incidence and predictors of severe anaemia with zidovudinecontaining regimens in African adults with

DOI: http://dx.doi.org/10.4314/ejhs.v28i1.9 
HIV infection within the DART trial. Antiviral Therapy 2005; 11:6. 741-749.

5. Mehta S, Jutur S, Gautam D. Hematologic Manifestations of HIV/AIDS. Medicine Update-2011.

6. Obirikorang C, Yeboah F. Blood hemoglobin measurements as a predictive indicator for the progression of HIV/AIDS in resource-limited setting. J Biomed Sci 2009; 16:102.

7. Bain B.J. The haematological features of HIV infection. Review. Br J Hematol. 1997;99:18.

8. Belperio P, Rhew D. Prevalence and outcomes of anemia in individuals with human immunodeficiency virus: a systematic review of the literature. Am J Med. 2004;116:27-43.

9. Mocroft A, Kirk O, Barton SE, Dietrich M, Proenca R, Colebunders R, et al. Anaemia is an independent predictive marker for clinical prognosis in HIV-infected patients from across Europe. AIDS. 1999; 13:943-50.

10. Moore RD, Forney D. Anemia in HIVinfected patients receiving highly active antiretroviral therapy. J Acquir Immune DeficSyndr 2002; 29: 54-7.

11. World Health Organization. Scaling up Antiretroviral Therapy in Resource limited Settings: Treatment Guidelines for a Public Health Approach; 2003 revision.

http://www.who.int/hiv/pub/prev care/en/arvrevision2003en.pdf

12. Miles SA. Hematopoietic growth factors as adjuncts to antiretroviral therapy. AIDS Res Hum Retroviruses 1992, 8: 1073-1080.

13. Groop man JE. Zidovudine intolerance. Rev Infect Dis. 1990, 12 (5): S500-S506.

14. Moyle G. Anemia in persons with HIV infection: prognostic marker and contributor to morbidity. AIDS Reviews,2002, 4, 13-20

15. Curkendall S, Richardson J, Emons M, Fisher A, Everhard F. Incidence of anemia among HIV-infected patients treated with highly active antiretroviral therapy. HIV Medicine 2007; 8. 483-490.

16. World Health Organization. March 2014 supplement to the 2013 consolidated guidelines on the use of antiretroviral drugs for treating andpreventing HIV infection recommendations for a public health approach. Accessed from: www. who.int

17. Food Medicine and Healthcare Administration and Control Authority of Ethiopia. Standard treatment guideline for primary hospitals. Third edition, 2014: 92-102

18. Subbaraman R, Chaguturu S, Mayer $H$, Flanigan T, Kumarasamy N. Adverse Effects of Highly Active Antiretroviral Therapy in Developing Countries. Clin Infect Dis 2007; 45: 1093-1101

19. World Health Organization. Haemoglobin concentrations for the diagnosis of anaemia and assessment of severity: VMNIS | Vitamin and Mineral Nutrition Information System. Report of a WHO scientific group, 2011. VMNS.

20. Clark KS, Hippel TG. Routine and point-ofcare testing in Hematology: Manual and semiautomated methods. In: Rodak BF, Fritsma GA, Keohane EM (eds.). Hematology: Clinical Principles and Application, $4^{\text {th }}$ edition. Elsevier Sounders, 2012: 172-91.

21. Panel on Antiretroviral Guidelines for Adults and Adolescents. Guidelines for the use of antiretroviral agents in HIV-1-infected adults and adolescents. Department of Health and Human Services (Last updated April 08, 2015).Available at:

http://www.aidsinfo.nih.gov/guidelines; accessed on 12/10/2016.

22. Meidiani M, Rezaei F ,Maracy MR, Avijgan M, Tayeri K. Prevalence, severity, and related factors of anemia in HIV/AIDS patients. J Res Med Sci2012, 17(2): 138-42.

23. Alem M, Kena T, Baye N, Ahmed R, Tilahun $S$. Prevalence of Anemia and Associated Risk Factors among Adult HIV Patients at the Anti- Retroviral Therapy Clinic at the University of Gondar Hospital, Gondar, Northwest Ethiopia, 2013; 2:662 doi:10.4172/scientificreports.662

24. Jam S, Ramezani A, Sabzvari D, Moradmand B, Seyed Ahmad, Jabbari H et al. A CrossSectional Study of Anemia in Human

DOI: http://dx.doi.org/10.4314/ejhs.v28i1.9 
ImmunodeficiencyVirus-Infected Patients in Iran. Arch Iranian Med 2009; 12:2:145-150.

25. Adane A, Desta K, Bezabih A, Gashaye A, Kassa D. HIV associated anemia before and after initiation of Anti-retroviral therapy at ART center of Minilik II Hospital. Ethiop Med J 2012; 50:1,13-21.

26. Lafaurie M, Collin F, Bentata M, Garre M, Leport C, Levy Y. Switch from zidovudine to non-zidovudine-containing regimens is associated with modest haematological improvement and no obvious clinical benefit: a sub study of the ANRS 099 ALIZE trial. J Antimicrob Chemotherapy 2008; 62: 11221129.

27. Moor RD, Forney D. Anemia in HIV-infected patients receiving highly active antiretroviral therapy. J Acquir Immune DeficSyndr 2002; 29:54-57.

28. Takuva S, Maskew M, Brennan A, Sanne I, MacPhail P, Fox M. Anemia among HIVInfected Patients Initiating Antiretroviral Therapy in South Africa: Improvement in Hemoglobin regardless of Degree of Immunosuppression and the Initiating ART Regimen. J Trop Med, 2013. Available at: http://dx.doi.org/10.1155/2013/162950. accessed on July 20,2016

29. SharmaSK. Zidovudine-induced anaemia in HIV/AIDS. Indian J Med Res2010, 132: 359361.

30. Agarwal D, Chakravaty J, Chaube L, Rai M, Agarwal RN, Sundar S. High incidence of zidovudine induced anaemia in HIV infected patients in eastern India. Indian $\mathrm{J}$ Med Res 2010; 132: 386-389.

31. Zhou J, Jaquet A, BissagneneE,Musick B, KaloustianWk, Maxwell N et al. Short-term risk of anaemia following initiation of combination antiretroviral treatment in HIV infected patients in countries in sub-Saharan Africa, Asia-Pacific, and central and South America. J Int AIDS Society, 2012; 15:5. DOI: 10.1186/1758-2652-15-5.

32. Milkias HW, Terefe WL, Yohannes AM, Hailesellasie KG. Incidence and Risk Factors of Anemia among HIV/AIDS Patients Taking Anti-Retroviral Therapy at Tertiary Hospitals in Addis Ababa, Ethiopia: A Retrospective Cohort Study. J HIV AIDS Infect Dis 2013, 2:303. DOI: 10.17303/jaid.2014.303.

33. Romanelli F, Empey K, Pomeroy C. Macrocytosis as an indicator of medication (Zidovudine) adherence in patients with HIV infection. AIDS patient care and STDs 2002;16(9):405-12

34. Kumarasamy N, Lai A, Cecelia AJ, saghayam S, Solomon S, Flanigan $\mathrm{T}$ et al. Toxicities and adverse events following generic HAART in south Indian HIV-infected individuals [abstract P189]. In: Proceedings of the 7th International Congress on Drug Therapy and HIV Infection (Glasgow, United Kingdom). 2004. 